\title{
Práticas de educação ambiental em organizações não governamentais
}

\author{
Environmental education practices in non-governmental organizations \\ Prácticas de educación ambiental en organizaciones no gubernamentales
}

Recebido: 16/10/2021 | Revisado: 23/10/2021 | Aceito: 01/11/2021 | Publicado: 02/11/2021

\author{
Stéphanie Assis \\ ORCID: https://orcid.org/0000-0003-1288-4643 \\ Universidade Federal do Rio Grande, Brasil \\ E-mail: stephassisxavier@gmail.com \\ Marta Regina Cezar-Vaz \\ ORCID: https://orcid.org/0000-0002-0754-7469 \\ Universidade Federal do Rio Grande, Brasil \\ E-mail:mrcezarvaz@gmail.com
}

\begin{abstract}
Resumo
Este trabalho é motivado pela pesquisa intitulada como Educação Ambiental não formal e Organização não Governamental de cunho social: incentivo a ações futuras em comunidades do Rio Grande do Sul, através da Universidade Do Rio Grande pelo Programa de Pós Graduação em Educação Ambiental. Para tanto, trata-se de uma revisão integrativa que tem como objetivo compreender como as Organizações Não Governamentais entendem, desenvolvem e praticam a EA. Conclui-se por meio da revisão, que é de extrema importância pensar a Educação Ambiental por meio das Organizações Não Governamentais, uma vez que, estas são canais de intermédio entre a sociedade civil e Estado. Além disso, percebe-se que há nas organizações diversos e diferentes tipos de práticas de Educação Ambiental, nas quais estão entre elas oficinas, minicursos e cursos de aperfeiçoamento, promoção de eventos e espaços de convivência. Desta forma as atividades permeiam entre as vertentes conservadoras e transformadoras da Educação Ambiental. Por fim, apesar da relevância e das várias atividades encontradas, conclui-se também de que há pouca produção acadêmica e com fácil acesso em relação ao tema, logo, espera-se que esta revisão integrativa possa orientar e auxiliar em estudos, pesquisas e práticas futuras de todos os grupos interessados.
\end{abstract}

Palavras-chave: Educação ambiental; Não formal; Organizações não governamentais; Práticas educativas.

\begin{abstract}
This work is motivated by the research entitled Non-formal Environmental Education and Non-Governmental Organization of a social nature: incentive to future actions in communities in Rio Grande do Sul, through the Universidad Do Rio Grande by the Post-Graduate Program in Environmental Education. Therefore, an integrative review aims to understand how Non-Governmental Organizations understand, develop and practice EE. The review concludes that it is extremely important to think about Environmental Education through Non-Governmental Organizations, since these are intermediary channels between civil society and the State. In addition, it is clear that there are several and different types of Environmental Education practices in organizations, which include workshops, short courses and improvement courses, promotion of events and spaces for social interaction. In this way, the activities permeate between the conservative and transformative aspects of Environmental Education. Finally, despite the relevance and the various activities found, it is also concluded that there is little academic production and easy access on the topic, therefore, it is expected that this integrative review can guide and assist in studies, research and practices futures of all interested groups.
\end{abstract}

Keywords: Environmental education; Not formal; Non-governmental organizations; Educational practices.

\begin{abstract}
Resumen
Este trabajo está motivado por la investigación titulada Educación ambiental no formal y organización no gubernamental de carácter social: incentivo a acciones futuras en las comunidades de Rio Grande do Sul, a través de la Fundación Universidad De Rio Grande por el Programa de Posgrado en Educación Ambiental. Por lo tanto, es una revisión integradora que tiene como objetivo comprender cómo las Organizaciones No Gubernamentales entienden, desarrollan y practican la EE. La revisión concluye que es de suma importancia pensar en la Educación Ambiental a través de Organizaciones No Gubernamentales, ya que estos son canales intermediarios entre la sociedad civil y el Estado. Además, es evidente que existen varios y diferentes tipos de prácticas de Educación Ambiental en las organizaciones, que incluyen talleres, cursos cortos y cursos de mejora, promoción de eventos y espacios de interacción social. De esta manera, las actividades permean entre los aspectos conservadores y transformadores de la Educación Ambiental. Finalmente, a pesar de la relevancia y las diversas actividades encontradas, también se concluye que existe poca producción académica y fácil acceso sobre el tema, por lo que se espera que esta revisión
\end{abstract}


integradora pueda orientar y coadyuvar en los estudios, investigaciones y prácticas futuras de todos. grupos interesados.

Palabras clave: Educación ambiental; No formal; Organizaciones no gubernamentales; Prácticas educativas.

\section{Introdução}

Atualmente vivencia-se um problema mundial conhecido como globalização, segundo Milton Santos (2000, p. 12) "A globalização é, de certa forma, o ápice do processo de internacionalização do mundo capitalista". Esse processo, é pautado em uma globalização para o neoliberalismo, desta forma, visando números e ignorando a qualidade de vida, pois, conforme o autor apresenta, existem três tipos de globalização: a da fábula, onde é fantasiado uma globalização para o avanço e desenvolvimento de todos igualmente; a da perversidade: como ela realmente é, da desigualdade social e econômica, da degradação ambiental, uma vez que visa a produção infinita através de materiais naturais finitos e a outra globalização: uma outra possível.

Ainda sobre a globalização da perversidade, com o crescimento da desigualdade social e econômica, da degradação ambiental e por conseguintes de problemas socioambientais, surgem em contrapartida os debates em torno da Educação Ambiental. Visando a os problemas causados pelo crescimento da degradação ambiental, ressurtem eventos que foquem no debate acerca da temática, entre eles a conferência de Estocolmo que irá incentivar posteriormente no Brasil a Rio 92 ou Cúpula da Terra. Através da Rio 92 incentiva-se a criação do Plano Nacional de Educação Ambiental (PNEA), a Lei no 9795 da Educação Ambiental e a inserção da temática de forma transversal no Plano Nacional Comum Curricular (PCN 's). Além da lei e planos, surge da Rio 91 a Agenda 21 que apresenta orientações por meio de objetivos aos países parceiros na busca por uma qualidade de vida voltada para a sustentabilidade ambiental.

No entanto, é importante salientar dois pontos, o primeiro de a Educação Ambiental não se coloca como a "salvação" dos problemas constituídos, o segundo de que é preciso contextualizar a EA, pois, a mesma possui uma história de descontextualização, levando a entender como 'meio ambiente'. Assim a Educação Ambiental é um processo educativo, que se pauta sobre questões ambientais e sociais, logo, socioambientais (Loureiro, 2003). Ainda que, está EA trata-se de ações educativas como ferramenta para o enfrentamento das problemáticas citadas e não como solução final das mesmas.

Para entendermos melhor a concepção de Educação Ambiental e como ela chega no ponto de ferramenta para o enfrentamento de problemas oriundos da globalização para o neoliberalismo, é preciso delimitar sobre qual EA estamos falando. Pois, pela própria história de descontextualização da EA dificulta-se a compreensão do que é, qual o objetivo e como fazer Educação Ambiental. Logo, constituem diferentes tipos de EA, formadas por visões sociais e naturais distintas, através de conflitos e diálogos por longo período (Loureiro, 2004). Assim, a EA se dá por meio de algumas visões, Loureiro (2004; 2003) apresenta as visões como conservadoras e transformadoras. Uma EA conservadora se fundamenta na reprodução, um exemplo desse tipo de Educação Ambiental são atividades que não se aprofundam na raiz do problema. Um exemplo, são atividades que trabalhem acerca do tema do lixo, mas vagam somente acerca da reciclagem, não pensam o consumismo.

No que se refere a uma Educação Ambiental transformadora ou crítica (Loureiro, 2003), esta é pautada em uma dialética, na qual forma conteúdo teorizados permanentes. A EA transformadora se dá por meio da práxis social, buscando a construção de novos patamares. Todavia, Loureiro (2003) atenta de que não se trata da ingenuidade de acreditar que somos todos condicionados a determinadas problemáticas, pois é preciso compreender que os problemas nos quais vivenciamos hoje são construídos pelas relações sociais, logo são históricos. Dito isto, a EA transformadora traz consigo a visão de que processos históricos nas relações e conflitos

A EA para transformação, é fundamentada na dialética, por meio da busca pela práxis social. Assim, a mesma compreende que as relações e os conflitos ambientais vivenciados são construídos historicamente. Por serem construídos historicamente é que essa transformação e busca por novos patamares sociais não são utópicos, uma vez que a construção da 
sociedade vive em constante mudança (Loureiro, 2004). A EA para transformação busca através das singularidades e do diálogo a busca pela participação para que se possa por meio desta atingir o sentimento de pertença e assim a responsabilidade e cidadania.

Além das visões apresentadas por Loureiro, existem as conhecidas correntes da EA que são apresentadas por Sauvé (2005) nas quais tratam de vertentes que podem ou não conversar entre si, além disso, permeiam entre a concepção conservadora e transformadora da EA. Logo, atentando de que não existe uma EA única e reafirmando que apesar de não existir uma EA correta, existem nelas ideologias e objetivos sobre o tipo de sociedade que se espera, já que é formada por disputas de poderes e conflitos.

Por sua vez, a participação por meio da interação e da manifestação dos diferentes interesses proporciona a cidadania. Pois, por meio dessa interação os indivíduos podem compartilhar e dialogar acerca das necessidades reais que vivenciam e assim se articular para o enfrentamento das mesmas. Como espaços de participação são vários os espaços onde essa acontece, todavia, se atentar que para uma mudança macrossocial é preciso que a mesma se dê em espaços públicos, como conselhos. Nesse ínterim as ONG se põem como um dos canais de diálogo entre a sociedade civil e espaços de poder público, principalmente por estas organizações estarem dominando o campo da Educação (Rodrigues; Loureiro, 2012) assim sendo capazes de proporcionar abertura do dialogo ente o Estado e sociedade civil e ainda para articular ações que visem mudanças.

Desta forma, entendo os problemas socioambientais e as origens do mesmo, compreendendo a EA como processo educativo, seu caráter transformador e as ONG como um canal para a participação da sociedade civil em diferentes espaços e de articulação da mesma para o enfrentamento das problemáticas, chegamos a justificativa pela construção desta Revisão Integrativa (RI). O trabalho motivou-se pela pesquisa intitulada como Educação Ambiental não formal e Organização não Governamental de cunho social: incentivo a ações futuras em comunidades do RS, através da Fundação Universidade De Rio Grande (FURG) pelo Programa de Pós Graduação em Educação Ambiental (PPGEA). Assim, buscando compreender as práticas de EA pelas ONG.

Portanto tem se como tema as práticas de EA em ONG, logo a questão problema orientadora desta revisão é Quais práticas em EA estão sendo desenvolvidas em OSC e ONG? A hipótese é de que há nas ONG diferentes práticas em EA que permeiam entre conservadoras à crítica. Logo, delimitou-se como objetivo geral: Compreender como as OSC/ONG entendem/desenvolvem/praticam a EA. Por conseguinte, como objetivos específicos estão:
$\rightarrow \quad$ Compreender como as ONG entendem a EA.
$\rightarrow \quad$ Identificar os desafios na prática em EA nas ONG.
$\rightarrow \quad$ Identificar necessidades que incentivam as práticas de EA em ONG.
$\rightarrow \quad$ Apontar as contribuições que práticas em EA ofertam para o público e ONG.

Posto as considerações iniciais, a seguir será apresentada a metodologia realizada durante a pesquisa bem como os resultados e as discussões acerca dos mesmos.

\section{Metodologia}

\subsection{Tipo de estudo}

Conforme mencionado, optou-se por uma revisão sistemática partindo do modelo integrativo. Para dar início a metodologia desta RI levamos em consideração as orientações de Whittemore e Knafl (2005) Botelho, Cunha e Macedo (2011) e Crossetti (2012). Além de ressaltar a importância de uma RI, uma vez que a mesma permite ao pesquisador conhecer o que já fora produzido acerca de sua pesquisa e ainda por meio da mesma permite também a geração de novos conhecimentos (Whittemore; Knafl. 2005 e Botelho; Cunha; Macedo, 2011). Os autores também abordam a importância da rigidez 
metodológica para que a RI tenha sua validação científica e que não se perca nenhuma informação, obtendo o maior número de produções sobre a temática possível. Para isso, ambos trazem etapas que podem auxiliar o pesquisador no processo de construção de sua revisão, assim, apresentadas no tópico a seguir.

\subsection{Etapas da revisão integrativa}

São as etapas abordadas pelos autores: estágio de identificação do problema (momento em que se identifica o tema, questão problema, estratégias de busca como descritores, critérios de inclusão e exclusão e bases de procura); Estágio de pesquisa de literatura (ensejo em que se inicia a exploração de produção nas bases de busca por meio dos critérios postos e se faz a pré seleção através da leitura de títulos, palavras chaves e resumos); Estágio de avaliação de dados (Avaliação das produções selecionadas por meio da leitura na íntegra e categorização dos mesmos); Estágio de análise de dados (feita a categorização passa-se a fazer a análise dos dos conteúdos). Conforme Botelho, Cunha e Macedo (2011) a análise tende a ser narrativa nesse tipo de revisão. Por fim, o estágio de apresentação de dados no qual se trata da elaboração de um documento a ser apresentado ou publicado com os resultados e discussão da busca.

\subsection{Etapas iniciais}

Tendo as orientações dos aportes teóricos bases deste estudo passou-se ao estágio primeiro, pensando o tema, a questão orientadora do processo, os objetivos e os critérios de busca, conforme mencionados anteriormente. Assim, levando em consideração os temas e objetivos colocados neste trabalho, tem se como descritores: seguir: Educação Ambiental e Organizações não Governamentais; Educação Ambiental e Organizações da Sociedade Civil; Práticas de Educação Ambiental e Espaços não formais. O primeiro e o segundo descritor foram postos pensando que algumas organizações necessitam de cnpj para se tornarem não governamentais, todavia há muitas organizações sem o documento que também atuam neste segmento, sendo nominadas como as Organizações de Sociedade Civil. Logo para se obter o máximo possível de informações foram postos os dois conceitos. Também, salientamos que está se tratou de uma delimitação inicial, assim através da fase de exploração em uma pré busca de material, foi identificado o descritor "práticas educacionais" como uma ferramenta importante nesta busca, sendo assim incluído neste grupo.

No que se refere aos critérios de inclusão, foi levado em consideração o ano em que a Educação Ambiental tornouse lei e assim delimitando como espaços possíveis de suas práticas os formais e não formais de educação. Também foram levados em consideração o ano em que as ONG se institucionalizaram e passaram a ser também espaços educativos (Fernandes, 1994). Além disso, foram considerados a nossa língua materna, tendo o português e a região geográfica onde a Universidade em que realizamos nossas pesquisas se posiciona e o país de origem da pesquisa (ao Sul do país, próximo ao Uruguai e como país próximo a Argentina) optando pelo Espanhol e a língua universal. Dessa maneira, se pôs como critérios de inclusão: Trabalhos publicados a partir de 1999; Trabalhos em Português); Espanhol; Inglês e periódicos revisados por pares.

Em relação aos critérios de exclusão, estão: trabalhos que não abordam EA em ONG e/ou OSC; não tenham descrito práticas de Educação Ambiental em ONGS/OSC em seus títulos, e/ou resumos; trabalhos com acesso limitado ao texto integral. Logo, para a busca foram selecionadas as bases: Institute Of Education Sciences (ERIC); Scientific Eletronic Library Online (SCIELO); Publicação Online de Educação e Metodologia (EDUC@) e Directory Of Open Access Journal (DOAJ). Feitas estas primeiras etapas, passamos para o estágio de busca de literatura, conforme o próximo tópico. 


\subsection{Estágio de pesquisa de literatura}

Este tópico tem como objetivo apresentar o processo de seleção do estudo, logo, será posto detalhamento das buscas e seus processos. Antes de dar início a este estágio foram feitas algumas buscas exploratórias com o intuito de testar os critérios de busca e descritores. Durante a fase exploratória foram identificadas as necessidades do uso de filtros em algumas das plataformas. Assim, com o intuito de manter um padrão nas buscas e garantir a elegibilidade do estudo, os filtros incluídos nas buscas serão descritos. A seguir, será apresentado uma breve descrição de como foram feitas as procuras nas plataformas.

Iniciou-se as buscas por meio da base ERIC com os descritores (educação ambiental) AND (organização não governamental), no entanto, não foram apresentados resultados, tendo isso em vista foi feita novamente a busca mas com os descritores em inglês. Em seguida, ao utilizar (Environmental education) AND (Practice) AND (Non-governmental organization) e com o filtro de revisado por pares surgem 10.188 resultados. Tendo o número elevado de resultados, buscou-se com o intuito de delimitar a busca dentro do tema, acrescentar os seguintes filtros: educação ambiental e práticas educacionais. Posto os filtros, tem-se como resultado 284 trabalhos. Delimitada a busca, seguiu-se para seleção prévia dos trabalhos através da leitura dos títulos, palavras chaves e/ou descritores e resumo.

Após a seleção dos trabalhos, seguiu-se a busca na ERIC, uma vez que ainda não haviam sido esgotadas as possibilidades por meio dos descritores. Assim, a próxima busca deu-se pelos descritores (Práticas de educação ambiental) AND (espaço não formal) no qual apresentou 1 resultado. Novamente optou-se então pela busca em inglês. Todavia, a busca apresentou 16.951 resultados então acrescentou-se o restante dos descritores, ficando (Environmental education) AND (practices) AND (non-formal space) AND (civil society organization) utilizando-se o filtro Educação Ambiental, obtendo o resultado de 54 trabalhos. Assim, feita a análise dos resultados e esgotada os descritores passei para a base de dados seguinte.

Seguindo para a próxima base, a busca se deu pela plataforma SCIELO. A primeira busca foi feita pelos descritores (educação ambiental) AND (organização não governamental), sem filtros, resultando somente em 1 trabalho, no qual foi selecionado por atender os critérios e estar dentro do tema. Entretanto foi feita uma segunda tentativa utilizando (educação ambiental) AND (organização da sociedade civil) mas não houve resultados para a busca. Assim, optou-se por utilizar a sigla de Organização Não Governamental, ficando (educação ambiental) AND (ONG), no qual apresentou 6 resultados. Seguindo a procura, utilizou-se os descritores (práticas de educação ambiental) AND (não formal) resultando em 8 trabalhos. Esgotadas as possibilidades na língua portuguesa, realizou-se a busca na língua inglesa com os mesmos descritores utilizados na ERIC: (Environmental education) AND (Practice) AND (Non-governmental organization). Todavia não houve resultados, então 'jogou-se' com os descritores e suas posições e o mesmo ocorreu, desta forma finalizando a busca na plataforma SCIELO.

Dando continuidade, para a busca na plataforma Educ@ iniciou-se com os descritores (Educação Ambiental) AND (Organização Não Governamental) obtendo 1 resultado. Tendo o baixo resultado, foi feita uma procura com os mesmos descritores em inglês e espanhol, no entanto não houve resultados. Por conseguinte, foram utilizados (Educação Ambiental) AND (Organização da Sociedade Civil) também nas três línguas e não houveram resultados. Logo, visualizando os descritores utilizados por outros trabalhos já selecionados, busquei então o teste com (Educação) $A N D(O N G)$, uma vez que, a plataforma identifica palavras separadas e não frases, assim tendo 31 resultados. Os resultados foram incluídos na análise, pois, houveram selecionados dentro dos critérios de inclusão, finalizando a busca na plataforma.

Encaminhando-se para a última plataforma selecionada, a busca feita na base de dados da DOAJ iniciou-se pelos descritores (Educação Ambiental) AND (Organização Não Governamental) tendo um resultado de 6 trabalhos. Todavia, nenhum dos trabalhos abordavam a EA em ONG ou práticas de EA em ONG, logo foi modificado para a língua inglesa, encontrando 22 trabalhos. Também foi feita uma busca dos mesmos descritores em espanhol, entretanto houveram somente dois resultados nos quais não condizem com a temática. Por fim, foi feita a busca com os descritores (Práticas em Educação 
Ambiental) AND (Não formal) não tendo nenhum resultado, assim finalizando a busca na base. Findada a busca pela literatura, passou-se então para a organização dos dados coletados, conforme apresentados a seguir.

\section{Estagio de Avaliação dos Dados}

Neste estágio é feita a leitura na íntegra e seleção final dos artigos para a análise (Wittemore; Knafl, 2005). Portanto, após a busca nas bases de pesquisa foram encontrados ao total 409 trabalhos. Destes, foi feita uma seleção prévia partindo da leitura de títulos, palavras chaves e/ou descritores e resumos, todos levando em consideração os critérios de inclusão e exclusão. Após a seleção prévia dos artigos foi dada a continuidade através da leitura na íntegra dos documentos selecionados. Neste momento, houve dificuldades para a continuidade na leitura de alguns documentos selecionados, pois, os mesmos se tratavam de documentos privados, onde havia o acesso ao resumo, porém não ao texto na íntegra. Antes de se fazer o descarte dos textos foram enviados e-mails aos autores dos mesmos solicitando, se possível, o documento, todavia não houve retornos. Para fins de organização e melhor visualização dos dados obtidos segue abaixo o barema dos resultados.

Barema: Resultados da busca.

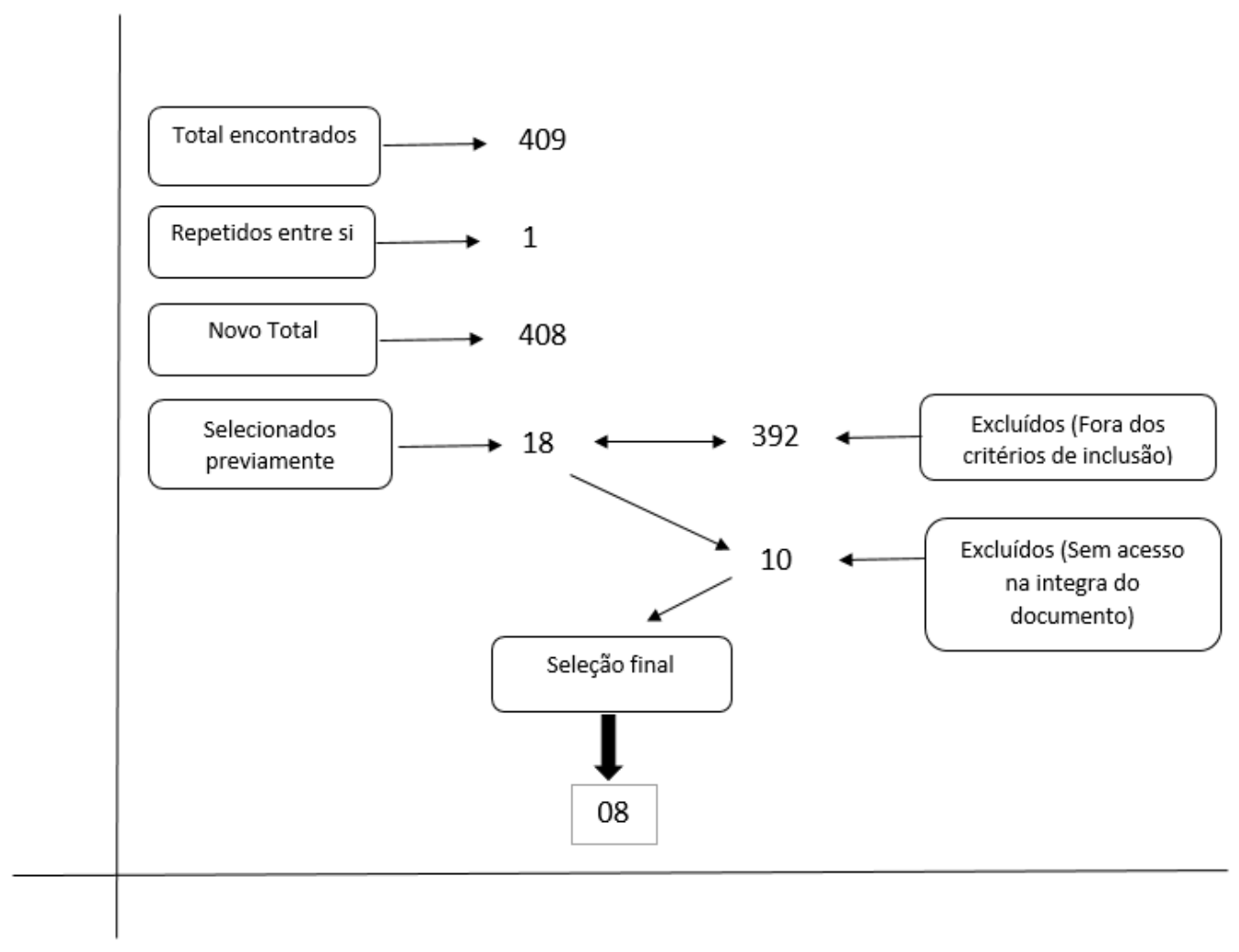

Fonte: Autores.

Conforme o gráfico de fluxo ou barema, foram selecionados previamente 18 trabalhos e excluídos 392, as exclusões de deram por não atender os critérios de inclusão. Além disso, a maioria dos trabalhos estavam fora do tema, pois não abordam a Educação Ambiental em ONG ou OSC, assim, justificando a exclusão dos trabalhos. Conforme anteriormente pontuado e apresentado no gráfico, houveram trabalhos que foram selecionados previamente, mas, posteriormente durante a seleção final não puderam ser acessados na íntegra lavando a exclusão dos mesmos. Deste modo, restando para a análise desta revisão 8 artigos, abaixo segue o quadro com mais detalhes dos documentos analisados. 
Quadro 1. Trabalhos selecionados e analisados.

\begin{tabular}{|c|c|c|c|}
\hline Título & Autores & Ano de publicação & $\begin{array}{l}\text { Tipo de pesquisa/ } \\
\text { metodologia }\end{array}$ \\
\hline $\begin{array}{l}\text { Inovação em educação } \\
\text { ambiental na cidade e na } \\
\text { floresta: o caso Oela }\end{array}$ & Elie Ghanem. & 2013 & Estudo de caso \\
\hline $\begin{array}{l}\text { O desenho infantil na ótica da } \\
\text { ecologia do desenvolvimento } \\
\text { humano }\end{array}$ & $\begin{array}{l}\text { Luciane Germano Goldberg; } \\
\text { Maria Angela Mattar Yunes; } \\
\text { José Vicente de Freitas; }\end{array}$ & 2005 & Reflexão sobre práticas \\
\hline $\begin{array}{l}\text { The contribuition of NGO in } \\
\text { enviromental: an avaluation of } \\
\text { stakeholders perception }\end{array}$ & Virginia Tristão; José Tristão. & 2016 & $\begin{array}{l}\text { Reflexão de práticas de EA em } \\
\text { ONG através do método } \\
\text { prospectivo Delphi. }\end{array}$ \\
\hline $\begin{array}{l}\text { "Lugar do lixo é no lixo": } \\
\text { estudo de assimilação da } \\
\text { informação }\end{array}$ & $\begin{array}{l}\text { Carla Tavares. Isa; Maria } \\
\text { Freire; }\end{array}$ & 2003 & $\begin{array}{l}\text { Análise de depoimentos e } \\
\text { práticas }\end{array}$ \\
\hline $\begin{array}{l}\text { Educação ambiental no Rincão } \\
\text { Gaia: pelas trilhas da saúde e da } \\
\text { religiosidade numa paisagem } \\
\text { ecológica }\end{array}$ & $\begin{array}{l}\text { Carlos Alberto Steil; Isabel } \\
\text { Cristina de Moura Carvalho; } \\
\text { Erica Onzi Pastori; }\end{array}$ & 2010 & Etnografia fenomenológica \\
\hline $\begin{array}{l}\text { A crise socioambiental e a } \\
\text { atuação } \\
\text { ambientalistas de no }\end{array}$ & $\begin{array}{l}\text { Jéssica do Nascimento } \\
\text { Rodrigues; Carlos Frederico } \\
\text { Bernardo Loureiro; }\end{array}$ & 2021 & Reflexão sobre EA em ONG 's. \\
\hline $\begin{array}{l}\text { Despertando os sentidos da } \\
\text { educação ambiental }\end{array}$ & José Matarezi. & 2006 & $\begin{array}{c}\text { Apresentação de resultados de } \\
\text { práticas }\end{array}$ \\
\hline $\begin{array}{l}\text { Organizações } \quad \text { não } \\
\text { governamentais ambientais } \\
\text { regionais: entre resistência e a } \\
\text { utopia, algumas reflexões }\end{array}$ & $\begin{array}{l}\text { Jussara da Silva Tavares; Vera } \\
\text { Lucia S. Botta Ferrante; }\end{array}$ & 2015 & $\begin{array}{l}\text { Pesquisa direta junto à ONG e } \\
\text { revisão bibliográfica. }\end{array}$ \\
\hline
\end{tabular}

Fonte: Autores.

Por fim, feita a seleção e a relação dos trabalhos iniciou-se a fase de elaboração das categorias para análise. Para elaborar a categorização foram buscados alguns aportes teóricos que auxiliassem nesse processo. Assim, conforme Meirelles, Cendón e Almeida (2016) a categorização precisa seguir alguns passos, pensando nisso foram postos alguns critérios para organizar as categorias, são eles: não haver na mesma categoria mais de um critério (cuidar para não haver subtópicos excessivos); as categorias devem abranger todos os documentos a serem analisados; a classificação deve excluir mutuamente, sendo bem delineadas para evitar confusão no momento da análise; por fim, o cuidado com a quantidade de categorias, não há uma regra quanto a isso, todavia o autor orienta para o cuidado para ser objetivo. Deste modo, pautando-se nessas orientações as categorias foram pautadas a partir da leitura e fichamento dos trabalhos e objetivo da RI. Logo, são: 1. Compreensão da Educação Ambiental; 2. Práticas desenvolvidas; 3. Desafios das práticas; 4. Incentivos que levam às práticas; 5; Contribuições da Educação Ambiental para as ONG; Determinadas as categorias seguem-se para o estágio de análise dos dados.

\section{Estágio de Análise dos Dados}

Esta fase compõe a análise dos dados obtidos para organização dos resultados, análoga à análise dos dados das pesquisas convencionais, esta fase demanda uma abordagem organizada para ponderar o rigor e as características de cada estudo (Souza, Silva, Carvalho, 2010, p. 104). Nesse sentido, conforme também orientado pelos autores Souza, Silva e Carvalho (2010) foram realizadas categorizações e por conseguinte uma análise por evidências. Todavia, por se tratar de uma 
revisão sobre as práticas, a evidências analisadas foram sobre os tipos de cada prática realizada e a compreensão da EA pelas ONG.

Desta forma, os dados das pesquisas selecionadas foram organizados pelas categorias. Assim fez-se a redução dos dados através das divisões das informações em grupos. O objetivo desta redução foi simplificar a leitura dos dados, assim as categorizações foram feitas através de diferentes elementos como: práticas identificadas nos estudos; desafios das práticas citadas; incentivos que levam as práticas de EA nas ONG; contribuições das práticas de EA para as ONG e as pessoas que participam delas; por fim, as vertentes da EA que os estudos apresentam. Crossetti (2012) orienta que as apresentações das análises nesse tipo de estudo tendem a ser narrativas, assim, feita a categorização e organização dos dados através da redução por grupos, iniciou-se a escrita narrativa dos resultados e discussões, conforme apresentados a seguir.

\section{Aspectos Eticos}

Não foi necessário a submissão ao comitê de ética, uma vez que, conforme a resolução no 510, 2016, é solicitado que a pesquisa utilize de acesso ou consulta ao público (pessoas) e por se tratar de uma revisão integrativa de literatura a mesma não encaixa no grupo solicitado.

\section{Resultados e Discussão}

\subsection{Compreensão da Educação Ambiental}

Conforme visto anteriormente sobre o que é Educação Ambiental, sabe-se que a mesma apresenta-se no geral por meio de duas facetas, como conservador ou comportamentalista e emancipatório, crítico ou transformador (Loureiro, 2004). Dentro dessas faces, há outras possíveis classificações, conhecidas como correntes da EA nas quais permeiam entre a conservadora e a transformadora. Desta forma, buscou-se durante a análise dos entender a compreensão das ONG sobre a EA. Ou seja, por meio de qual corrente de EA a ONG atua.

Para realizar esta análise, utilizou-se como fundamentação teórica de Sauvé (2005), em seu texto sobre cartografias da Educação Ambiental a autora busca apresentar algumas das correntes da EA. Embora estas se apresentem separadamente, é importante lembrar que, conforme a mesma descreve, não é intuito delimitar uma EA certa ou fragmentar essa ciência da EA, pois sabe-se que é possível a prática de uma ou mais correntes na mesma ação. Todavia, o texto serve para compreender os objetivos de determinadas práticas e a concepção de EA que instituições e educadores têm em suas atividades, assim, justificando a escolha pelo texto para essa análise.

Dando continuidade, durante a leitura dos textos pode-se perceber que as ONG possuem múltiplos direcionamentos, como ONG de cunho social ou diretamente voltadas à questão ambiental. No entanto, mesmo com direcionamentos distintos, todas realizam atividades de EA. Por meio das atividades e dos objetivos das mesmas, percebeu-se que parte das práticas são voltadas a uma EA que vise a sensibilização do ser humano em relação ao ambiente em que vive. Nesse sentido, também são realizadas diversas práticas que visem o holismo, a relação ser humano $\mathrm{x}$ ambiente (planeta terra) x outros seres vivos (Steil, Carvalho e Pastori, 2010) e a relação ecológica, na qual se refere ao sentimento do indivíduo com o espaço e a ação sob ele. Conforme Goldoberg, Yunes e Freitas (2005, p. 99) descreve, a questão ecológica reside também nas relações dos indivíduos a partir da habitação destes ambientes e nas dinâmicas interações entre os mais variados espaços mentais, sociais e geográficos.

Através dessas ideias, percebe-se que a concepção da EA se dá por meio das correntes naturalista, humanista e holística. Pois, conforme Sauvé, em relação a corrente naturalista, está está pautada na "lição de coisas" ou aprendizagem por imersão, ainda que "a corrente naturalista pode ser associada mais especificamente ao movimento de "educação para o meio 
natural" (nature education) e a certas proposições de "educação ao ar livre" (outdoor education)" (Sauvé; 2005, p. 19). Sobre a corrente humanista,

Esta corrente dá ênfase à dimensão humana do meio ambiente, construído no cruzamento da natureza e da cultura. O ambiente não é somente apreendido como um conjunto de elementos biofísicos, que basta ser abordado com objetividade e rigor para ser melhor compreendido, para interagir melhor. (Sauvé; 2005, p. 19)

Por fim, a holística,

A corrente holística não associa proposições necessariamente homogêneas, como é o caso das outras correntes. Algumas proposições, por exemplo, estão mais centradas em preocupações de tipo psicopedagógico (apontando para o desenvolvimento global da pessoa em relação ao seu meio ambiente); outras estão ancoradas numa verdadeira cosmologia (ou visão do mundo) em que todos os seres estão relacionados entre si, o que leva a um conhecimento "orgânico" do mundo e a um atuar participativo em e com o ambiente (Sauvé; 2005, p. 27).

Percebe-se que as correntes apesar de distintas têm semelhanças, uma vez que todas se referem ao sentimento do indivíduo com determinado espaço em que está inserido seja local ou planetário. Além disso, são semelhantes às suas práticas que tendem a partir da observação e/ou experiência, como na corrente naturalista onde parte de uma aprendizagem por imersão. Em seguida, há outras correntes da EA identificadas nas ONG através de atividades que visem uma EA para o manejo sustentável e de intervenção prática (Ghanem, 2013) além de emancipatória, transformadora e crítica (Matarezzi, 2006; Tavares; Freire; 2003) e uma EA que busque a transformação por meio da participação dos indivíduos (Tavares; Ferrante; 2008).

Desta forma, identifica-se também a corrente práxica, na qual segundo Sauvé (2005, p. 41) busca "Aprender em, para e pela ação". Desenvolver competências de reflexão". Da eco educação, na qual busca "experimentar o meio ambiente para experimentar-se e formar-se em e pelo meio ambiente. Construir sua relação com o mundo, com outros seres que não sejam humanos" (p.41). Por fim, a corrente crítica, que busca "desconstruir as realidades socioambientais visando a transformar o que causa problemas" (p. 41). Para aprofundar a compreensão sobre essas correntes e que tipo de práticas correspondem às mesmas, no subtópico a seguir será feita uma breve descrição das práticas em EA que estão sendo realizadas pelas ONG.

\subsection{Práticas de EA desenvolvidas pelas ONG}

Conforme posto, este item irá abordar quais as práticas de EA estão sendo desenvolvidas pelas ONG, auxiliando também no aprofundamento sobre a compreensão de EA trazida pela ONG. Para isso será feito algumas descrições das práticas relacionadas com as correntes discutidas anteriormente. Assim, dando início, entre as atividades desenvolvidas que se relacionam com as correntes humanista, naturalista e holística estão: atividades de desenho com crianças, pois, segundo os autores, por meio de desenhos é possível interpretar a relação da criança com o lugar em que habita, por meio de símbolos que revelam conceitos. Além disso, esse tipo de prática visa uma EA que desenvolve a percepção do ambiente que o ser humano vive através da sensibilidade (Goldberg; Yune; Freitas, 2005).

Seguindo, também permeiam essas correntes trilhas interpretativas, oficinas, hortas pedagógicas, cursos de formação, nos quais tem como desafios, "conscientizar a sociedade sobre os riscos socioambientais que gera, possibilitando mudanças de comportamento na sua relação com a natureza" (Tristão, Tristão, 2016). Ressalta que conforme Sauvé (2005), esse tipo de corrente tende a praticar atividades de imersão, logo as trilhas interpretativas se encaixam nessa perspectiva, uma vez que os autores Stel, Carvalho e Pastori (2010) apresentam as atividades da ONG GAIA por meio de uma imersão que visão uma 
experiência sensorial. Além da trilha trazida pelos dois trabalhos, ambos apresentam também cursos nos quais vão de ervas ao aperfeiçoamento para produção e consumo de alimentos agroecológicos.

Nas atividades voltadas para correntes práxica, eco educativa e crítica, estão: atividades de luthier, na qual se trata de uma ONG na Amazônia uma vez que identificada a vulnerabilidade social das pessoas que residem no local e o número de madeiras que não tinham finalidades resultando no projeto do caso OELA. Esta atividade surge de demandas da população construída juntamente com o coletivo, a proposta é a transformação das realidades e proporcionar atividades com os recursos disponíveis, além disso se tornou uma opção para que as pessoas que vivem na região não precisem buscar emprego em outro lugar (tendo em vista as vulnerabilidades) e possam ao mesmo tempo cuidar do espaço que vivem.

Outra atividade nessas correntes está projetos como a recicloteca, a atividade é composta por oficinas destinada a todos os públicos com horários agendados (frequentemente visitado por escolas). O projeto surgiu da necessidade de trabalhar o tema do lixo, uma vez que se percebia na cidade do Rio De Janeiro (localização da ONG) um grande volume de lixo nas ruas. Durante a análise foi posta relacionada a atividade com as correntes porque o autor menciona, que a ONG tem como objetivo desse projeto não somente levar a informação, mas proporcionar um ressignificado ao tema, ainda de que é preciso decodificar e para então chegar a conscientização. Além disso, os autores complementam que a ONG entende essa tomada de conscientização como a chave inicial para uma real transformação de valores e então de realidades. Logo, a atividade, que poderia também ser relacionada com recursista/ conservacionista (Sauvé,2005) põe-se aqui como práxica e/ou crítica.

Por fim, outras atividades dentro dessas vertentes da EA estão ações que visam a participação da sociedade civil em espaços de tomadas de decisões de políticas públicas como conselhos. As ONG proporcionam atividades que articulam a sociedade civil e por vezes as representam em determinados espaços como os conselhos, através dessas ações possibilitam a participação dos indivíduos além da reivindicação de políticas públicas que atendam necessidades reais. Através dessa participação é garantido os direitos sociais e ambientais dos cidadãos. Tavares e Ferrante (2010, p. 13) reafirmam,

Neste sentido, a sociedade civil tem se articulado, participado em conselhos, comitês, fóruns locais, globais e demais instâncias, expressão da efetivação da democracia participativa, de forma individual ou organizada em ONGs, as quais apresentam maiores iniciativas de articulação e, ao mesmo tempo, de ampliação da abrangência de suas ações, podendo influir nos espaços político-administrativos estabelecidos, na proposta de políticas públicas que garantam os direitos dos cidadãos.

Desta forma, percebe-se que as ONG atuam em diversas correntes da EA por meio de diferentes práticas, desde a sensibilização em relação ao sentimento do indivíduo com o espaço em que vive, a relação com o meio ambiente e outros seres, a mudança de atitudes e valores e a reivindicação de direitos junto ao Estado. Finalizando este subtópico, compreende-se por quais vertentes da EA as ONG caminham e quais as práticas da EA estão sendo feitas em seus espaços. No entanto, durante as leituras, percebeu-se que as atividades surgiram por meio de necessidades locais, regionais e até nacionais e mundiais. Além disso, também foram ao longo das descrições percebidos que a implementação e desenvolvimento das atividades perpassam por muitos desafios, pensando nisso, fez se um levantamento desses desafios e incentivos para que outras ONG, estudantes e pesquisadores possam ponderar e se preparar através desta RI quando planejar atividades semelhantes ou fazer os estudos acerca do tema.

\subsubsection{Práticas de EA em ONG: Desafios e incentivos}

Eventualmente, através das leituras e anotações percebe-se que os desafios também são os incentivos das práticas de EA nas ONG. Pois, em suma, a maior parte das atividades são incentivadas pela degradação ambiental, onde, frente a problemática, as ONG se põem como um lugar de ação da EA para o enfrentamento da mesma. As atividades visam a articulação e participação da sociedade civil para enfrentamento de determinadas problemáticas. Além disso, são mencionados 
nos textos a falta de políticas públicas em relação a questões socioambientais como o acesso ao saneamento básico e algumas das consequências da globalização (como crescimento capital em detrimento da qualidade de vida, desemprego, fome, e problemas ambientais como queimadas, desmatamento e outros) (Tristão, Tristão, 2016).

Os desafios das práticas se relacionam com os incentivos as mesmas, pois,

A baixa articulação entre os diferentes atores sociais envolvidos na promoção do pensamento ambientalista (órgãos públicos, associações de base, ONGs, sindicatos) acarreta uma pulverização e fragmentação de iniciativas e não contribui para a materialização de intervenções sistematizadas e positivas, influenciadoras e formadoras, não só de opinião pública,mas de ações transformadoras. (Tavares; Frerrante, 2008 p. 14)

Logo, se o que incentiva as ONG é a promoção da participação do indivíduo ao coletivo como forma de articulação seja para o repensar ações, sensibilização referente ao modo de se relacionar com o espaço e o outro ou para reivindicar direitos, ou repensar a cultura, este também é o seu desafio. Todavia, apesar do impasse apresentado, a EA é para a ONG o que a ONG é para EA, um espaço ou ferramenta para que sejam alcançados os objetivos, a seguir será melhor discorrido acerca desse parecer.

\subsubsection{Contribuições da Educação Ambiental para as ONG}

Conforme observou-se durante a análise, é nítido o quanto a ONG é um espaço possível para a prática de EA em suas diferentes vertentes por meio de diversas ações. Compreende-se também de que as ONG já estão inseridas em determinados espaços e portanto têm um vínculo com as pessoas que residem ao seu redor. Entretanto, apesar da relação existente, percebese como desafios a articulação e participação da sociedade civil, órgão de poder público e mercado nos projetos e ações. Em contrapartida, também é possível visualizar que as atividades de EA nesses espaços proporcionam um fortalecimento de vínculo entre as ONG e os participantes e usuários.

Para exemplificar, no caso da ONG OELA, a atividade em EA transformou a ONG e auxiliou que jovens tivessem uma atividade que fortaleça seus vínculos e auxiliassem no seu sustento e cuidado com o meio ambiente (Ghanem, 2013). Nesse mesmo sentido, Tristão e Tristão, (2016, p;48) complementam que a EA se coloca como uma proposta de transformação social não somente das relações mas das realidade, pois,

A educação ambiental não formal praticada pelas organizações do terceiro setor apresenta- -se como uma nova proposta pedagógica voltada para a mudança de hábitos, atitudes e práticas sociais que indiquem uma solução para o quadro de degradação socioambiental que aflige o mundo contemporâneo.

Logo, pode-se dizer que a EA também é um espaço para a ONG buscar a articulação e participação das pessoas, pois, as atividades possuem potencial para ir além do "chamar atenção" mas de problematização e transformação social. A Educação Ambiental tem assim sua dimensão epistemológica para a produção de conhecimento, dessa produção a reflexão e o potencial de criticidade. Logo, por meio de suas ações é possível a transformação.

Loureiro (2015) traz o questionamento sobre o porquê e de que a EA seria ou pode se tornar crítica, segundo o autor, sua característica básica é colocar racionalmente sob questão toda verdade socialmente apresentada, afirmada e legitimada e refutar todo e qualquer pensamento que dissocia sociedade de natureza. Nesse sentido, as atividades apresentadas pelos trabalhos que trazem a EA nas ONG apresentam essas condições conforme o exemplo da OELA, portanto a Educação Ambiental nesses espaços tem uma contribuição positiva em auxiliar a reflexão sobre o pertencimento do ser humano e a sua não dissociação com o espaço em que vive.

Em complemento a esse deslumbramento, Toledo, Giati e Jacobi (2014, p. 633) refletem a problemática como uma questão que envolve temas físicos, sociais, econômicos, políticos e culturais. Assim, as ações de intervenção por meio da EA 
em ONG podem se dar através de diversas áreas de propostas, abrangendo desta forma as oficinas, os cursos, as trilhas e outros. Desta forma, mesmo que a ação não vise uma transformação ou criticidade pode contribuir em outro aspecto, desde a economia de quem se encontra em vulnerabilidade econômica à qualidade de vida das pessoas que participam das atividades.

\section{Conclusão}

Infere-se que são diversas as práticas de Educação Ambiental realizadas pelas ONG. Dentre as práticas mais citadas estão a promoção de eventos e oficinas que proporcionem a informação. Utilizando-se dos fundamentos teóricos, Loureiro (2003) traz a informação como um dos meios de instigar a participação da sociedade civil, em consonância as práticas que partem da informação segundo os trabalhos analisados também visam a participação e ressignificação dos sentidos. Outras práticas comumente utilizadas nas ONG estão os minicursos ou cursos de aperfeiçoamento, estes também tem em seu caráter a participação e informação, no entanto, soma-se às propostas o fomento a uma atividade que auxilie no desenvolvimento econômico de determinada região ou grupo. Por fim, também são abordadas pelas ONG as trilhas que tem em seu cerne a ressignificação e sensibilização em relação ao homem x natureza x ambiente.

Desse modo, considerando as atividades e as fundamentações acerca da EA, pode-se concluir que dentre as práticas de EA ofertadas pelas ONG permeiam diferentes correntes. Conclui-se assim que há potencialidade das ONG como espaços para a Educação Ambiental, bem como, a Educação Ambiental como ferramenta para o fortalecimento dos grupos e articulação dos mesmos para o enfrentamento de problemáticas socioambientais. Desta forma, partindo deste trabalho, orienta-se que profissionais da área da EA e das ONG se articulem para buscar por meio de diferentes ações que refletem o social e ambiente, produzir EA em conjunto com a comunidade civil. Dentre as atividades desencadeadoras do processo, indicamos então as que foram apresentadas e obtiveram resultados positivos como trilhas, atividades que abrangem produção para o sustento das famílias, atividades que englobem a arte como danças, pinturas, observações e outros. Ainda, orientamos por meio desse trabalho, que essas não sejam "a atividade de Educação Ambiental” mas que possam ser uma abertura para se fazer a Educação Ambiental, ou seja, que a partir destas possam coletivamente pensar outras ações.

\section{Referências}

Crossetti, M. G. M. (2012) Revisão Integrativa de pesquisa na enfermagem o rigor cientifico que lhe é exigido. Rev. Gaúcha Enferm.33(2):8-9. Porto Alegre.

Botelho, L. L. R., Cunha, C. C. de A; \& Macedo, M. (2011) O método da revisão integrativa nos estudos organizacionais. Gestão E Sociedade, Belo Horizonte-MG.121-136. https://doi.org/10.21171/ges.v5i11.1220

Fernandes, R. C. (1994) Privado porém público: o terceiro setor na América Latina. -

Ghanem, E. (2013) Inovação em educação ambiental na cidade e na floresta: o caso Oela. Cad. Pesqui. 43 (150). https://doi.org/10.1590/S010015742013000300014

Goldoberg, L.G., Yunes, M., A. M. \& Freitas, J, V. (2005) O desenho infantil na ótica da ecologia do desenvolvimento humano. Psicol. Estud. 10 (1). https://doi.org/10.1590/S1413-73722005000100012

Loureiro, C. F. B. (2003) Premissas teóricas para uma educação ambiental transformadora. Ambiente \&Amp; Educação, 8(1), 3754. https://periodicos.furg.br/ambeduc/article/view/897

Loureiro, C. F. B. (2004) Educação ambiental e gestão participativa na explicitação e resolução de conflitos. Gestão em Ação, 7(1). http://arquivo.ambiente.sp.gov.br/cea/2011/12/FredericoLoureiro.pdf

Loureiro, C. F. B. (2015) Educação Ambiental e Epistemologia Crítica. Carlos Frederico B. Loureiro. REMEA. https://doi.org/10.14295/remea.v32i2.5536

Matarezzi, J. (2006) Despertando os sentidos da educação ambiental. Educar, (27), 181-199. Editora UFPR. http://educa.fcc.org.br/pdf/er/n27/n27a12.pdf

Meirelles, M. R. G., Cendón, B. V. \& Almeida, P. E. M. (2016) Comparação do processo de categorização de documentos utilizando palavras-chave e citações em um domínio de conhecimento restrito. TransInformação, 28(1):87-96. https://www.scielo.br/j/tinf/a/k6xqTtL LCZ6TxrYWzbPsxLw/?format=pdf\&lang=pt

Rodrigues, J. N., \& Loureiro, C. F. B. A (2012) crise socioambiental e a atuação de ONGs ambientalistas no campo educacional. Linhas Crí-ticas, 18(36), 379-394. http://educa.fcc.org.br/pdf/lc/v18n36/v18n36a09.pdf 
Research, Society and Development, v. 10, n. 14, e301101421882, 2021

(CC BY 4.0) | ISSN 2525-3409 | DOI: http://dx.doi.org/10.33448/rsd-v10i14.21882

Sauvé, L. Uma cartografia das correntes em educação ambiental. Educação ambiental: pesquisa e desafios. Artmed, 2005. https://edisciplinas.usp.br/pluginfile.php/4586522/mod_resource/content/1/sauve\%20correntes\%20EA.pdf

Santos, M. Por uma outra globalização: do pensamento único à consciência universal. Milton Santos, Record- 2000.

Souza, M. T., Silva, M. D., \& Carvalho, R. Revisão integrativa: o que é e como fazer Einstein. 2010; 8(1 Pt 1). https://www.scielo.br/j/ eins/a/ZQTBkVJZqcWrTT34cXLjtBx/?format=pdf\&lang=pt

Steil, C. A., Carvalho, I. C. M., \& Pastori, E. O. Educação ambiental no Rincão Gaia: pelas trilhas da saúde e da religiosidade numa paisagem ecológica. Educação, 33(1), 54-64. http://educa.fcc.org.br/pdf/reveduc/v33n01/v33n01a06.pdf

Tavares, C., \& Freire, I. M. "Lugar do lixo é no lixo": estudo de assimilação da informação. Ci. Inf., 32(2), 125-135, https://doi.org/10.1590/S010019652003000200013

Tavares, J. S., \& Ferrante, V. L. S. Organizações Não Governamentais Ambientais Regionais: entre a resistência e a utopia, algumas reflexões. Jussara da Silva Tavares. Vera Lucia S. Botta Ferrante. Revista UNIARA, 2008. https://doi.org/10.25061/2527-2675/ReBraM/2007.v11i2.175

Toledo, R. F., Giatti, L. L., \& Jacobi, R. P. A pesquisa-ação em estudos interdisciplinares: análise de critérios que só a prática pode revelar. Comunicação, Saúde e Educação - Interface (Botocatu) 18(51):633-46. 2014. 10.1590/1807-57622014.0026

Tristão, V. T. V., \& Tristão, J. A. M. The contribution NGOS of environmental education: and avaluation the stakeholders perception. Ambient. soc. 19 (03) • Jul-Sep $2016 \cdot h$ ttps://doi.org/10.1590/1809-4422ASOC132656V1932016

Wittemore, R., \& Knalfl, K. Methodological issues in nursing research the integrative review: update methodology. Journal Of Advanced Nursing. 52(5), 546553. 02/2005. 